\title{
Comunicación
}

\section{Lesiones Histopatológicas y Aislamiento Bacteriológico en Gamitanas (Colossoma macropomum) Aparentemente Sanas}

\author{
Histopathological Lesions and Bacteriological Isolation in Apparently \\ Healthy Gamitanas (Colossoma macropomum)
}

\author{
Fernando Ramos E. ${ }^{1,4}$, Nieves Sandoval C. ${ }^{1}$, Siever Morales C. ${ }^{2}$, Guadalupe \\ Contreras S. ${ }^{3}$, Alberto Manchego S. ${ }^{2}$
}

\section{Resumen}

\begin{abstract}
El objetivo del presente estudio fue determinar lesiones histopatológicas y aislar agentes infecciosos en órganos y tejidos de gamitanas (Colossoma macropomum) aparentemente sanas. Se colectaron 40 especímenes juveniles en una piscigranja de la zona de Ucayali, Perú. Se tomaron muestras de hígado, bazo, riñón, estómago, branquias y músculo para análisis histopatológico y de los cinco primeros para análisis bacteriológico. En el hígado se encontró degeneración hidrópica (39/40), en el riñón se observó degeneración hidrópica y necrosis tubular (40/40), con incremento de centros melanomacrófagos en la periferia de los túbulos, en el estómago se observó degeneración hialina en las células de la mucosa (25/40), y en las branquias se observó infiltración de células inflamatorias en filamento branquial (40/40), hiperplasia del epitelio interlaminar (40/40) e hiperplasia del filamento branquial (18/40). No se encontraron lesiones en bazo. Se encontraron parásitos mixosporidios en branquias (2/40), riñón (40/40) y músculo (12/40) y parásitos monogeneos en branquias (6/40). Se aislaron, en baja frecuencia, bacterias potencialmente patógenas (Aeromonas hydrophila y Edwardsiella tarda) en branquias y órganos internos, pero sin relación con las lesiones histopatológicas.
\end{abstract}

Palabras clave: gamitana, Colossoma macropomum, centros melanomacrófagos, mixosporidios, monogeneos

\footnotetext{
${ }^{1}$ Laboratorio de Histología, Embriología y Patología Veterinaria, ${ }^{2}$ Laboratorio de Microbiología y Parasitología Veterinaria, Facultad de Medicina Veterinaria, Universidad Nacional Mayor de San Marcos, Lima, Perú

${ }^{3}$ Centro de Investigaciones IVITA, Universidad Nacional Mayor de San Marcos, Pucallpa, Perú

${ }^{4}$ E-mail: somarfresc@hotmail.com
}

Recibido: 12 de marzo de 2015

Aceptado para publicación: 20 de agosto de 2015 
The aim of this study was to determine histopathological lesions and bacterial isolates in organs and tissues of clinically healthy gamitanas (Colossoma macropomum). Forty juveniles were collected from a fish farm in the region of Ucayali, Perú. Samples were collected from kidney, liver, spleen, stomach, gills and muscle for histopathological and bacteriological analysis. In the liver was found hydropic degeneration (39/40), in kidney, hydropic degeneration and tubular necrosis (40/40) with an increase of melanomacrophage centres in the periphery of the tubules, in stomach, hyaline degeneration (25/40), and in gills, infiltration of inflammatory cells in branchial filament (40/40), interlamellar epithelium hyperplasia (40/40) and hyperplasia in branchial filament (18/40). No lesions were found in the spleen. Myxosporean parasites were found in gills (2/40), kidney (40/40) and muscle (12/40), and monogenean parasites in gills (6/40). Bacteria were isolated in low frequency, including potentially pathogenic bacteria (Aeromonas hydrophila and Edwardsiella tarda) in gills and organs, but without association with the histopathological findings.

Keywords: gamitana, Colossoma macropomum, melano-macrophage centres, myxosporea, monogenean

\section{INTRODUCCIÓN}

En el Perú, la gamitana (Colossoma macropomun) se cultiva en las regiones de Loreto, San Martín, Madre de Dios, Ucayali y Cusco, y a nivel internacional se cultiva en Brasil, Colombia, Venezuela, Bolivia y Panamá. Es un pez rústico, onmívoro, con preferencia por el alimento vegetal y bastante dócil, que habita en lagunas y áreas inundadas por los ríos, y llega a la madurez sexual a los cinco años (FONDEPES, 2014).

Con el desarrollo de su cultivo se ha incrementado la presencia y frecuencia de agentes patógenos que pueden afectar la eficiencia productiva de las piscigranjas (Dezon et al., 2004). La mayor parte de los cuadros patológicos guardan estrecha relación con la calidad de agua y el estado nutricional del pez (González y Heredia, 1998).

Entre las principales enfermedades que han sido reportadas en la gamitana se encuentran la causada por la bacteria Flexibacter columnaris, la enfermedad del punto blanco causada por el parásito Ichthyophthirius multifilis y la septicemia hemorrágica bacteriana causada por Aeromona hydrophila; así como micosis y parasitismo por monogeneos como Dactylogirus sp (Eufrasio y Palomino, 2006). Asimismo también se reportan infecciones por Piscinoodinium pillulari y Perulernaea gamitanae (Delgado et al., 2011).

Las deficiencias en el manejo, así como condiciones desfavorables en las piscigranjas, facilita que los peces bajen sus defensas naturales, predisponiéndolos a enfermedades infecciosas y no infecciosas. La acuicultura es una actividad económica importante en la Amazonía; sin embargo, no se dispone de estudios sobre alteraciones histopatológicas en gamitanas en el país. Por otro lado, en Colombia se han hecho estudios en la especie Piaractus brachypomus sobre la anatomopatología comparada de las alteraciones branquiales (Eslava, 1999).

En el presente estudio, se identifican y describen lesiones histopatológicas y aislamiento de bacterias en gamitanas criadas en una piscigranja de la zona de Pucallpa, Perú. 


\section{Materiales y Métodos}

El muestreo se realizó en la Estación Experimental del Centro de Investigaciones IVITA-Pucallpa, en el departamento de Ucayali. La evaluación bacteriológica e histopatológica de las muestras se realizó en el Laboratorio de Bacteriología y en el Laboratorio de Patología Veterinaria de la Facultad de Medicina Veterinaria de la Universidad Nacional Mayor de San Marcos, en Lima, Perú.

Se seleccionaron 40 gamitanas, aparentemente sanas (con reflejo de fuga y sin alteraciones en piel, aletas y branquias), en fase juvenil y sin distinción de sexo. Los peces fueron sacrificados mediante un corte medular.

Se realizó el examen externo para descartar lesiones o ectoparásitos. Se desinfectó la superficie del pez con alcohol al $70 \%$ y se realizó la necropsia según las técnicas de rutina (Reimschuessel et al., 1988). Se tomaron muestras de branquias, hígado, riñón, bazo y estómago y fueron colocadas en el medio de transporte Stuart para cultivos bacteriológicos. Asimismo, se tomaron muestras adicionales de estos órganos y de músculo en formalina tamponada al $10 \%$ para la evaluación histopatológica mediante inclusión en parafina y tinción con hematoxilina-eosina.

En el laboratorio, las muestras se cultivaron en Agar Infusión Cerebro Corazón (BHI), Agar Tripticasa de Soya (TSA) con $8 \%$ de sangre de ovino desfibrinado, TSA + $8 \%$ de sangre de ovino desfibrinado + ampicilina, y en medios selectivos MacConkey, Yersinia, agar xilosa y lisina desoxicolato (agar XLD) a $37{ }^{\circ} \mathrm{C}$ durante 2448 horas. Las colonias resultantes fueron aisladas y coloreadas con la tinción Gram. Asimismo, para la identificación de las bacterias, las colonias fueron previamente aisladas y se sometieron a las pruebas bioquímicas de Sulfuro Indol Motilidad (SIM), agar Simmons Citrato, agar Hierro Triple Azúcar
(TSI), agar lisina y, finalmente, se realizó el índice analítico de perfil (API 20E y API 10S).

Las alteraciones histopatológicas fueron clasificadas como trastornos inflamatorios, circulatorios, del crecimiento, degenerativos y parasitarios, según ha sido propuesto por Reimschuessel et al. (1992). Además, fueron clasificadas de acuerdo a su extensión como escasa, leve, moderada y severa si la lesión se observaba hasta el $25 \%$, entre el 25 y $50 \%, 50$ a $75 \%$ y por encima del $75 \%$ del corte, respectivamente.

\section{Resultados}

Los trastornos y alteraciones histológicas en los órganos y tejidos de las gamitanas se presentan en el Cuadro 1. En el caso del hígado, la alteración más frecuente fue la degeneración hidrópica, caracterizada por vacuolas de borde irregular en el citoplasma de los hepatocitos (Fig. 1a). En el caso del riñón fueron la degeneración hidrópica y la necrosis tubular, observándose además la presencia de esporas de mixosporidios en el citoplasma de las células tubulares y la infiltración de centros melanomacrófagos sobre las células degeneradas y necrosadas de los túbulos que presentaban los mixosporidios (Fig. 1b). En el caso del tejido muscular, se encontró la presencia de quistes de mixosporidios entre las fibras musculares, sin evidenciarse respuesta inflamatoria (Fig. 1c).

En el caso de alteraciones histológicas en branquias (Cuadro 1), el trastorno degenerativo más frecuente fue la hiperplasia interlaminar (Fig. 1d), así como una moderada infiltración de células inflamatorias, mayormente de tipo mononuclear, en el filamento branquial. En forma similar al músculo, se observaron alteraciones parasitarias, como quistes de mixosporidios en el arco branquial y en el filamento branquial (Fig. 1e) y presencia de parásitos monogeneos entre las laminillas branquiales (Fig. 1f). 
Cuadro 1. Alteraciones histopatológicas en órganos y tejidos de gamitana (Colossoma macropomum) según el tipo de trastorno $(n=40)$

\begin{tabular}{|c|c|c|c|c|c|c|c|}
\hline \multirow[t]{2}{*}{ Órgano } & \multirow[t]{2}{*}{ Trastorno } & \multirow[t]{2}{*}{ Normal } & \multicolumn{4}{|c|}{$\begin{array}{c}\text { Tipo de lesión } \\
(\mathrm{n})\end{array}$} & \multirow{2}{*}{$\begin{array}{l}\text { Alteración } \\
(\%)\end{array}$} \\
\hline & & & Escaso & Leve & Moderado & Severo & \\
\hline \multicolumn{8}{|l|}{ Hígado } \\
\hline \multicolumn{8}{|c|}{ Degenerativo } \\
\hline & Degeneración hidrópica & 1 & 0 & 0 & 9 & 30 & 97.5 \\
\hline \multicolumn{8}{|c|}{ 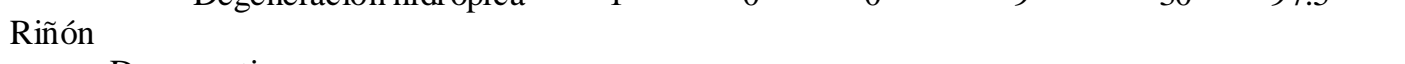 } \\
\hline \multicolumn{8}{|c|}{ Degenerativo } \\
\hline & Degeneración hidrópica & 0 & 21 & 14 & 4 & 1 & 100.0 \\
\hline & Necrosis tubular & 0 & 21 & 14 & 4 & 1 & 100.0 \\
\hline \multicolumn{8}{|c|}{ Parasitario } \\
\hline & $\begin{array}{l}\text { Esporas de } \\
\text { mixosporidios }\end{array}$ & 0 & 21 & 14 & 4 & 1 & 100.0 \\
\hline \multicolumn{8}{|c|}{ Otros } \\
\hline & $\begin{array}{l}\text { Infiltración de centros } \\
\text { melanomacrófagos }\end{array}$ & 0 & 21 & 14 & 4 & 1 & 100.0 \\
\hline \multicolumn{8}{|l|}{ Músculo } \\
\hline \multicolumn{8}{|c|}{ Parasitario } \\
\hline & $\begin{array}{l}\text { Quistes de } \\
\text { mixosporidios }\end{array}$ & 28 & 12 & 0 & 0 & 0 & 30.0 \\
\hline \multicolumn{8}{|c|}{ Branquias } \\
\hline \multicolumn{8}{|c|}{ Inflamatorio } \\
\hline & $\begin{array}{l}\text { Infiltración de células } \\
\text { inflamatorias }\end{array}$ & 0 & 0 & 0 & 40 & 0 & 100.0 \\
\hline \multicolumn{8}{|c|}{ Del crecimiento } \\
\hline & $\begin{array}{l}\text { Hiperplasia del epitelio } \\
\text { interlaminar }\end{array}$ & 22 & 0 & 10 & 4 & 4 & 100.0 \\
\hline & $\begin{array}{l}\text { Hiperplasia en } \\
\text { filamento }\end{array}$ & 22 & 0 & 10 & 4 & 4 & 45.0 \\
\hline \multicolumn{8}{|c|}{ Parasitario } \\
\hline & $\begin{array}{l}\text { Quistes de } \\
\text { mixosporidios }\end{array}$ & 38 & 2 & 0 & 0 & 0 & 5.0 \\
\hline & Parásitos monogeneos & 34 & 6 & 0 & 0 & 0 & 15.0 \\
\hline \multicolumn{8}{|c|}{ Estómago } \\
\hline \multicolumn{8}{|c|}{ Degenerativo } \\
\hline & $\begin{array}{l}\text { Necrosis del epitelio de } \\
\text { la mucosa }\end{array}$ & 15 & 0 & 0 & 25 & 0 & 62.5 \\
\hline & Degeneración hialina & 15 & 0 & 0 & 25 & 0 & 62.5 \\
\hline
\end{tabular}

En el estómago se evidenciaron trastornos degenerativos como degeneración hialina, caracterizada por micro y macrogotas hialinas en el epitelio de la mucosa gástrica, y necrosis del epitelio de la mucosa (Fig. 2). No se encontraron lesiones en el bazo.
En el estudio microbiológico se aislaron ocho especies de bacterias, mayormente en muy baja frecuencia, a excepción de bacterias en branquias, donde se encontraron aislamientos positivos en más de la mitad de la población (Cuadro 2). 


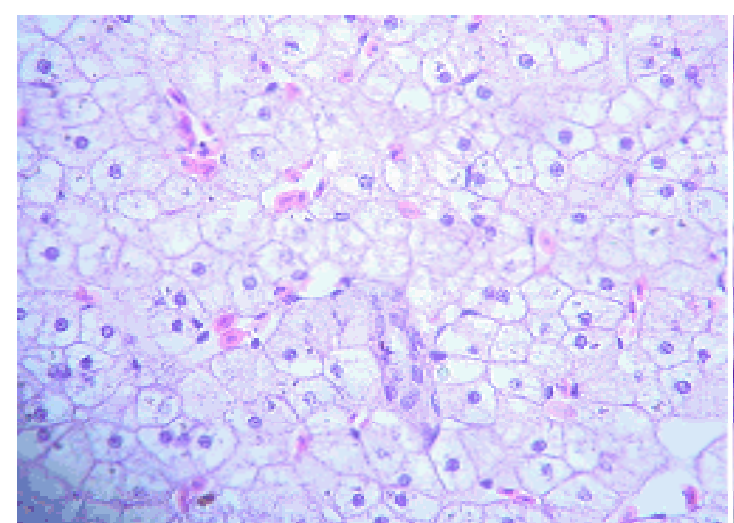

(a)

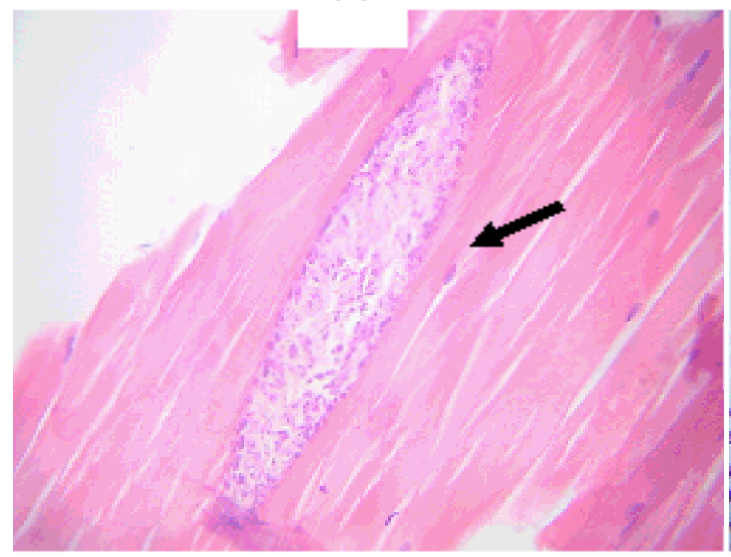

(c)

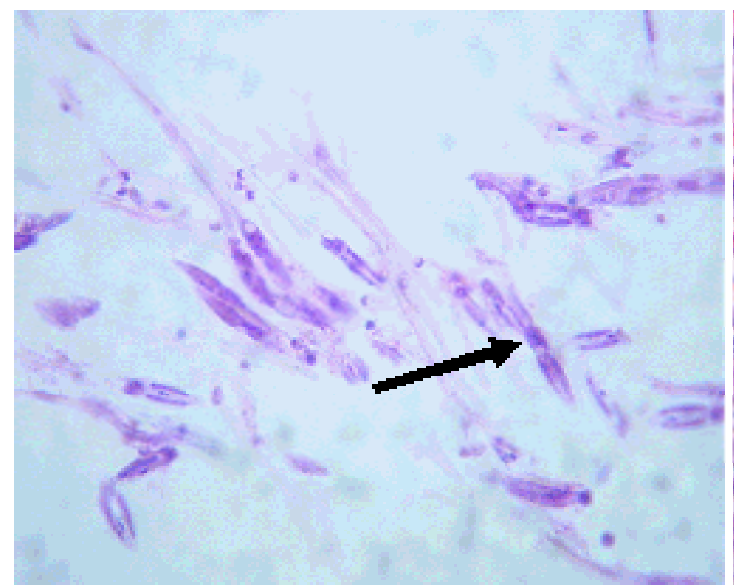

(e)

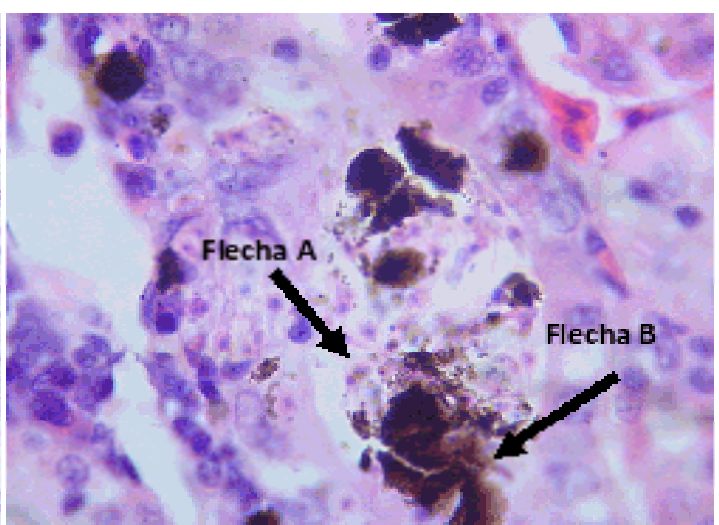

(b)

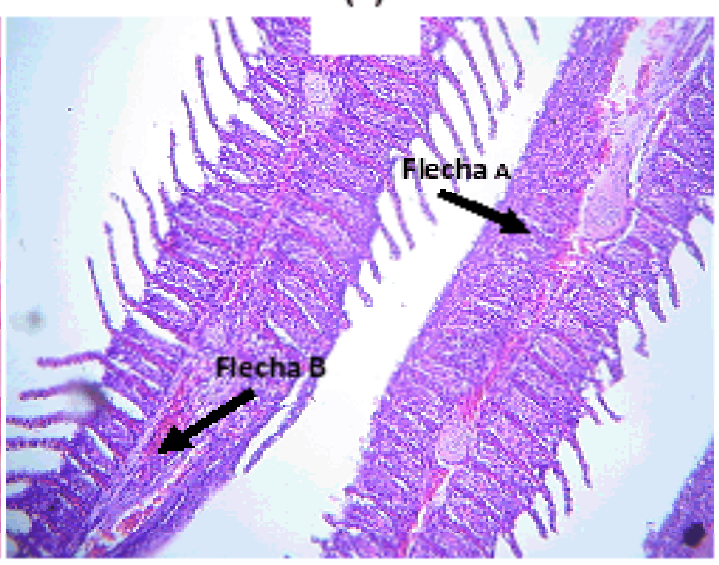

(d)

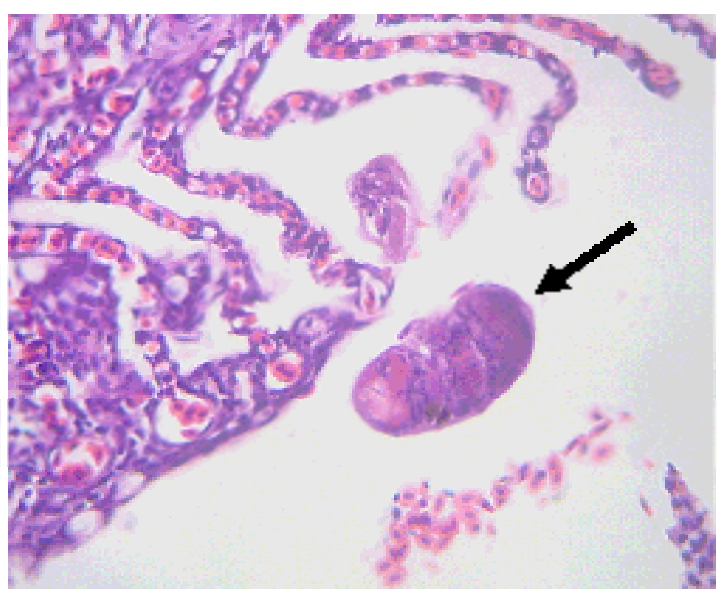

(f)

Figura 1. Cortes histológicos de órganos y tejidos de gamitana (Colossoma macropomum). (a) Hígado: se aprecia severa degeneración hidrópica en los hepatocitos. H\&E. 400x. (b) Riñón: formas libres de mixosporidios (flecha A) e infiltración de centros melanomacrófagos (flecha B) en la luz de los túbulos renales. H\&E. 1000x. (c) Músculo: quiste de mixosporidio en el músculo esquelético (flecha). H\&E. 400x. (d) Branquia: hiperplasia interlaminar (flecha A) y congestión en el filamento branquial (flecha B). H\&E. 400x. (e) Branquia: esporas de mixosporidios en el interior de un quiste en filamento branquial. Se aprecian las dos cápsulas polares (flecha). H\&E. 1000x. (f) Branquia: parásito monogeneo (flecha). H\&E. 1000x 


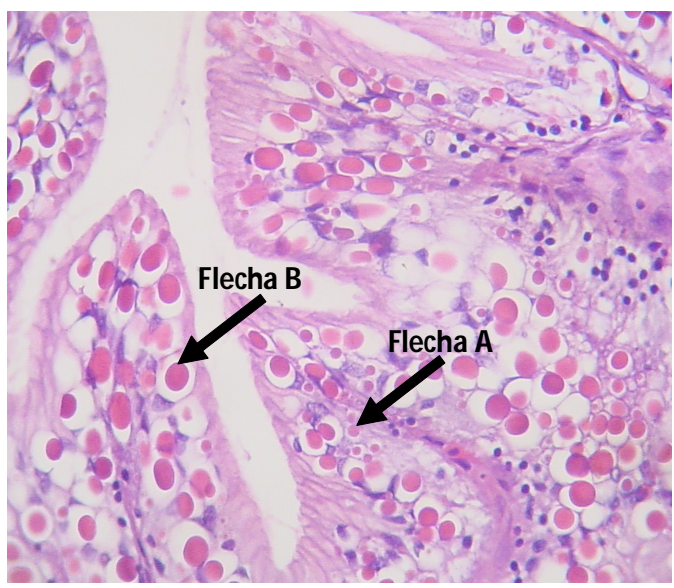

Figura 2. Microgotas (flecha A) y macrogotas hialinas (flecha B) en el epitelio de la mucosa gástrica de la gamitana (Colossoma macropomum). H\&E. 400x

\section{Discusión}

La elevada frecuencia de degeneración vacuolar hepática fue similar a los hallazgos de López et al. (2001) en hígado de salmonídeos. Tacon (1992) relaciona estas lesiones con altos niveles de ácidos grasos poliinsaturados en las dietas, que conllevan a cambios oxidativos en los lípidos (rancidez).

En todos los peces se encontraron formas libres de mixosporidios en el citoplasma de las células tubulares del riñón, así como degeneración y necrosis del epitelio tubular. En forma similar, Verján (2002) reportó degeneración de los túbulos renales en el $80 \%$ de Pyaractus brachypomus ( $\mathrm{n}=263$ ), relacionándolo a la presencia de mixosporidios. Asimismo, el incremento de centros melanomacrófagos, próximos y dentro de las células degeneradas y necrosadas encontrados en el presente estudio fueron igualmente observados por este autor. Estas lesiones pueden estar relacionadas a la presencia de formas libres de mixosporidios, ya que los melanomacrófagos son células de la respuesta inmunológica características de los teleósteos, las cuales aumentan en número y medida y se tornan más oscuros en procesos de infección (Ferguson, 2006); no obstante, también puede deberse a la presencia de algún otro agente patógeno o a la deficiente calidad del agua (Agius y Roberts, 2003). En el presente trabajo, si bien se observaron mixosporidios en todos los peces, no se encontraron signos clínicos ni mortalidad, dado que las lesiones fueron escasas y leves.

Las lesiones de hiperplasia del epitelio interlaminar y la hiperplasia del filamento encontradas en las branquias se atribuyen a una mala calidad del agua (Verján, 2002). Por otro lado, casos de hiperplasia así como de infiltración de células mononucleares en el filamento branquial pueden ser ocasionadas por parásitos; sin embargo, debido a la baja frecuencia de parásitos (15\% de monogeneos y $5 \%$ de quistes de mixosporidios), se podría asumir que las lesiones encontradas no tendrían un origen parasitario sino una mala calidad del agua.

Los quistes de mixosporidios en el arco y filamento branquial encontrados en el presente estudio han sido descritos por Molnár (2002) en las especies Myxobolus, Henneguya y Thelohanellus. Por otro lado, los parásitos monogeneos ubicados en las laminillas branquiales no causaron lesiones. Estos parásitos son usualmente indicadores de la pobre sanidad y deterioro de la calidad del agua (Kinkelin et al., 1991; Noga, 2000).

El 30\% (12/40) de los peces presentaba quistes de mixosporidios en el músculo esquelético con estadios esporogónicos inmaduros, no habiendo una reacción inflamatoria en la periferia ni daños en el tejido, coincidiendo con Noga (2000), que sostiene que la mayoría de los mixosporidios con estadios inmaduros producen una leve o nula respuesta inflamatoria y, generalmente, son encontrados como hallazgos incidentales en el trabajo de rutina diagnóstica.

La presencia de material hialino en el epitelio de la mucosa gástrica $(62.5 \%, 25 / 40)$ 
Cuadro 2. Frecuencia (\%) de aislamiento de bacterias en órganos y tejidos de gamitanas (Colossoma macropomum) aparentemente sanas $(\mathrm{n}=40)$

\begin{tabular}{lccccc}
\hline & Branquias & Hígado & Bazo & Riñón & Estómago \\
\hline Pseudomona fluorescens/putida & 72.5 & 20.0 & 20.0 & 12.5 & 5.0 \\
Edwardsiella tarda & 15.0 & 5.0 & 12.5 & 5.0 & 12.5 \\
Plesiomona shigelloides & 5.0 & 2.5 & 5.0 & - & 2.5 \\
Salmonella arizonae & 17.5 & 2.5 & - & 2.5 & 7.5 \\
Aeromonas hydrophila & 2.5 & - & - & 2.5 & - \\
Bacilus cereus & 5.0 & - & - & - & 5.0 \\
Serratia sp & 5.0 & - & - & - & 2.5 \\
Escherichia coli & 12.5 & - & - & - & - \\
Salmonella enterica & - & - & - & - & 2.5 \\
\hline
\end{tabular}

está relacionada a un exceso de proteína, deficiente digestibilidad de esta o inapropiada formulación del contenido proteico en la ración (Iregui et al., 2004). En este caso, el alimento contenía $28 \%$ de proteína, siendo suficiente un $20 \%$ para gamitanas en fase de crecimiento (Verján, 2002). Esto podría ser un indicativo de que las lesiones están relacionadas a trastornos del metabolismo proteico por un exceso de proteína, aunque no se puede descartar la baja digestibilidad o calidad de la proteína en la dieta.

Con respecto a los aislamientos bacteriológicos, se aislaron ocho especies de bacterias pero en muy baja frecuencia, y mayormente en branquias. Por otro lado, no se observaron lesiones histopatológicas compatibles con procesos infecciosos de tipo bacteriano. Es usual el aislamiento de bacterias saprofitas o contaminantes, siendo importante considerar la relación entre las lesiones y las especies bacterianas aisladas (Del Rio Rodríguez y Turnbull (1999). Aeromonas hydrophila y Edwardsiella tarda, dos de las especies aisladas son consideradas como patógenas en diversas especies de peces de cultivo (Sugita et al., 1995; Najiah et al., 2006), pero en este caso no estuvieron asociadas a las lesiones histopatológicas encontradas.

\section{Conclusiones}

- Las lesiones histopatológicas encontradas en gamitanas (Colossoma macropoтum) fueron mayormente escasas o leves aunque frecuentes, pero sin llegar a causar signos clínicos de enfermedad.

- Las gamitanas presentan niveles bajos de infección con mixosporidios.

- Las bacterias Aeromonas hydrophila y Edwardsiella tarda, aisladas en branquias y órganos internos, no tuvieron relación con el tipo de lesiones encontradas.

\section{Literatura Citada}

1. Agius C, Roberts RJ. 2003. Melanomacrophage centres and their role in fish pathology. J Fish Dis 26: 499-509. doi: 10.1046/j.1365-2761.2003.00485.x

2. Dezon DE, Zambrano J, Gonzalez I. 2004. Parasitosis en Colossoma macropomum (Pisces: Characidae) cultivado, ocasionada por los protozoos Ichthyophtirius multifilis (Fouquet) $\mathrm{y}$ Piscinoodinium pillulare (Schaperclaus). Agrobiología 16(1): 3-8. 
3. Del Rio Rodríguez RE, Turnbull JF. 1999. Aerobic microflora of imported tropical ornamental fish from Singapore and South America. Part1: Characterization. Fish Vet J 4: 1-16.

4. Delgado P, Delgado J, Arenas J, Ismino R. 2011. Massive infestation by Perulernaea gamitanae (Crustacea: cyclopoida: Lernaidae) in juvenile gamitana, cultured in the Peruvian Amazon). Vet Méx 42: 59-64.

5. Eslava P. 1999. Anatomo-patología comparada de las alteraciones branquiales de la cachama blanca (Piaractus brachypomus). Tesis de Maestría. Bogotá: Univ Nacional de Colombia. $250 \mathrm{p}$.

6. Eufrasio P, Palomino A. 2006. Manual de cultivo de gamitana. $2^{\text {da }}$ ed. Lima: FONDEPES. $102 \mathrm{p}$.

7. Ferguson H. 2006. Systemic pathology of fish. A text and atlas of normal tissues in teleosts and their responses in disease. $2^{\text {nd }}$ ed. Scotian Press. London. 367 p.

8. González JA, Heredia B. 1998. Cultivo de la cachama (Colossoma macropomum). Maracay, Venezuela: Fondo Nacional de Investigaciones Agropecuarias, Centro de Investigaciones Agropecuarias del Estado Guárico. 134 p.

9. Iregui A, Hernández E, Jiménez A, Pulido A, Rey A, Comas J, Peña L, et al. 2004. Primer mapa epidemiológico de las lesiones y enfermedades de los peces de Colombia. Bogotá: Univ Nacional de Colombia. $70 \mathrm{p}$.

10. Kinkelin P, Michel C, Ghittino P. 1991. Tratado de las enfermedades de los peces. España: Ed Acribia. 353 p.

11. López I, Cubillos V, Ernst S, Rosenfeld C. 2001. Frecuencia y distribución, según edad y estacionalidad, de patologías hepáticas en salmonídeos, provenientes de la X ${ }^{\mathrm{a}}$ a XII ${ }^{\mathrm{a}}$ Región de Chile. Periodo 1988-1998. Arch Med Vet 33: 193-202. doi: 10.4067/S0301-732X2001000200008
12. Martins ML, Moraes JR, Andrade PM, Schalch SH, Moraes FR. 2001. Piscioodinum pillulare (Schäperclaus, 1954) Lom, 1981 (Dinoflagellida) infection in cultivated freshwater fish from the northeast region of Sao Paulo State, Brazil. Parasitological and pathological aspects. Braz J Biol 61: 639644. doi: 10.1590/S1519-69842001000400013

13. Molnár K. 2002. Site preference of fish myxosporeans in the gill. Dis Aquat Org 48: 197-207. doi: 10.3354/dao048197

14. Najiah M, Lee SW, Lee KL. 2006. Phenotypic characterization and numerical analysis of Edwardsiella tarda in wild asian swamp eel, Monopterus albus in Terengganu. J Sustain Sci Mngt 1(1): 85-91.

15. Noga J. 2000. Fish disease. Diagnosis and treatment. Iowa, USA: Iowa State University Press. 367 p.

16. Reimschuessel R, May E, Bennett R, Lypsky M. 1988. Necropsy examination of fish. Vet Clin North Am Small Anim Pract 18: 427-433.

17. Reimschuessel R, Bennett RO, Lipsky M. 1992. Communications: a classification system for histological lesions. $\mathbf{J}$ Aquat Anim Health 4:135-143. doi: 10.1577/1548-8667(1992)004<0135:$\mathrm{CACSFH}>2.3 . \mathrm{CO} ; 2$

18. Sugita H, Tanaka K, Yoshinami M, Deguchi Y. 1995. Distribution of Aeromonas species in the intestinal tracts of river fish. Appl Environ Microbiol 61: 4128-4130.

19. Tacon A. 1992. Nutricional fish pathology. Morphological signs of nutrient deficiency and toxicity in farmed fish. Rome: FAO Fish Technical Paper N. ${ }^{\circ}$ $330.75 \mathrm{p}$.

20. Verján N. 2002. Sistematización y caracterización de las enfermedades de la cachama blanca (Piaractus brachypo$m u s)$ en algunas regiones de los Llanos Orientales y estudio de la enfermedad septicémica. Tesis de Maestría. Bogotá: Univ Nacional de Colombia. 250 p. 